\title{
МЕХАНИЗМ УПРАВЛЕНИЯ ФОРМИРОВАНИЕМ И РАЗВИТИЕМ ИННОВАЦИОННОЙ ЭКОСИСТЕМЫ ПРИ ПЕРЕХОДЕ К НОВОМУ ТЕХНОЛОГИЧЕСКОМУ УКЛАДУ
}

Современные технологические вызовы глобального характера переопределяют переосмысление традиционных форм и методов хозяйствования, экспериментирование с новыми бизнес-моделями. Динамичный формат последнего поколения бизнес-моделей - инновачионная экосистема, предназначение которой в создании благоприятных условий для самоорганизуючегося отбора и результативной реализации инновационных идей, проектов, а такэе эффективное взаимодействие всех участников. Анализ мирового опытта развития стартап-экосистем позволил связать уровень их успешности и конкурентоспособности с уровнем действенности их механизма управления при росте неопределенности и изменчивости макросреды. С использованием системного подхода разработана структурная схема механизма управления формированием и развитием инновационной экосистемы, дифференцированные элементы которого и связи межсу ними образуот основу для решения широкого круга проблем активизации инновачионных процессов и обеспечения поступательного роста инновационного бизнеса.

Ключевые слова: инновация, инновационная экосистема, изменениям, механизм, устойчивое pasвитue, cmapman.

\section{Anna Ter-Grigoryants, Marina Denshchik MECHANISM OF MANAGEMENT OF THE FORMATION AND DEVELOPMENT OF INNOVATIVE ECOSYSTEM IN THE TRANSITION TO NEW TECHNOLOGICAL STORAGE \\ Modern technological challenges of a global nature redefine the rethinking of traditional forms} and methods of managing, experimenting with new business models. The dynamic format of the latest generation of business models is an innovation ecosystem, the purpose of which is to create favorable conditions for self-organizing selection and effective implementation of innovative ideas and projects, as well as effective interaction of all participants. Analysis of the world experience of development of start-up ecosystems allowed us to link the level of their success and competitiveness with the level of effectiveness of their management mechanism with increasing uncertainty and variability of the macroenvironment. Using a systematic approach, a structural scheme of the mechanism for managing the formation and development of an innovation ecosystem has been developed, the differentiated elements of which and the connections between them form the basis for solving a wide range of problems in activating innovation processes and ensuring the viability of the innovation business.

Key words: innovation, innovation ecosystem, change, mechanism, sustainable development, start-up.

Bвedenue / Introduction. В условиях стремительного распространения новых технологий и знаний, глобальной конкуренции идей и образов будущего усиливается технологическое отставание российской экономики от стран-лидеров мирового инновационного соревнования. Российская экономика с позиций современных реалий хозяйствования и динамики ее инновационного развития может быть оценена двояко. С одной стороны, накоплены существенные фундаментальные и технологические разработки; имеется весомая научно-производственная, ресурсная и кадровая база, необходимая для успешной их реализации в конкретных отраслях народного хозяйства, разработана соответствующая законодательно-нормативная база и практически в каждом регионе созданы институты развития и активизации инновационной деятельности, в первую очередь в высокотехноло- 
гичных секторах национальной экономики [1]. С другой стороны, российские организации демонстрируют низкую инновационную восприимчивость, проблемными остаются вопросы трансфера и коммерциализации инновационных технологий, низок спрос на инновации, недостаточными являются объемы инвестиционно-финансовой поддержки инновационной сферы в целом и научно-образовательной в частности, сохраняются проблемы с качеством инновационного менеджмента в различных секторах экономической деятельности. Все это в комплексе обусловливает отстающий уровень инновационной активности российской экономики (8,5\% в 2017 г. против $10,4 \%$ максимального ее значения, достигнутого в 2011 г. [2]) по отношению к развитым и развивающимся странам. До сих пор не создана необходимая среда для инноваций, дающая стартапам и другим инновационным агентам лучшие возможности для достижения глобального успеха.

Все это повышает актуальность исследований проблем и особенностей формирования и устойчивого функционирования так называемых инновационных экосистем (ИЭС), интенсивное развитие которых, как показывает опыт глобальных стартап-экосистем (Кремниевая долина, Лондон, Пекин, Бостон, Нью-Йорк и др.), обеспечивает новый уровень конкурентоспособности национальной экономики в целом и территории ее локализации в частности через масштабирование и гармоничную трансформацию инновационного бизнеса. Если говорить о современной российской инновационной экосистеме, то она не являет собой единой комплексной системы, а сформированные ее структурные элементы (преимущественно инфраструктурные) зачастую функционируют неэффективной. Решение этой проблемы нами видится в построении результативно ориентированного механизма управления, идея которого состоит в управленческом воздействии, активизирующем и регулирующем взаимодействие всех участников инновационных процессов, локализованных в ИЭС.

Вопросы формирования и развития инновационных экосистем через переосмысление концепции национальной инновационной системы (К. Фримэн, Б. Лундвалл, Р. Нельсон, 80-90-е гг.) сообразно динамично меняющимся рыночным правилам рассмотрены в трудах зарубежных и российских специалистов: И. Агамирзяна, Д. Айзенберг, Р. Айреса, С. Бланка, Ч. Весснера, П. Глура, Д. Джексона, К. Дэвлина, Г. Ицковица, С. Клайна, Б. Кларка, Л. Копейкиной, А. Кулева, Ф. Кодами, М. Рассела, Э. Риса, В. Слободчикова, К. Факуды, Ч. Эдквиста, А. Яковлевой и др. Особенности разноуровневых ИЭС раскрыты в работах: Р. Аднера, Ф. Беккенбаха, Р. Бригеля, А. Бурке, С. Ватанэйба, Д. Гоктаса, М. Даскалакиса, С. Дерста, Я. Максвелла, Б. Меркона и др.

Поскольку устойчивое развитие ИЭС во многом предопределяется разнообразием составляющих ее участников, процессов, форм и видов их взаимодействия, находящихся под постоянным влиянием переменных внешней среды, то сложно говорить о достаточности целевой исследованности рассматриваемой проблематики, несмотря на широкий научный интерес и практический вклад ученых и специалистов в ее разработку. В частности, существует необходимость в переосмыслении используемых и разработке новых механизмов, позволяющих системно и быстро проходить весь путь от идей, изобретений и открытий до их коммерческого успеха, создавать инновационные возможности на пересечении продуктов, компаний и отраслей, одновременно развивая экономику территории и решая широкий комплекс других социально-экономических, организационно-управленческих и научно-практических задач проактивного развития в режиме самоорганизации и автоматизма устранения отклонений от заданных целевых параметров. В связи с этим целью исследования явилась выработка системного представления о логике структурирования механизмов формирования и развития инновационных экосистем в контексте происходящих изменений.

Maтериалы и методы / Materials and methods. Предметом исследования явились детерминирующие факторы и процессы построения и развития инновационной экосистемы при переходе к новому технологическому укладу. В качестве объекта выступила система механизмов, 
обеспечивающих создание благоприятной среды для взаимодействия инновационных агентов по поводу генерирования и коммерциализации инноваций. Теоретическо-методологическая основа исследования представлена работами отечественных и зарубежных ученых в области теории систем и инноваций, развития сетевого взаимодействия и экосистемного подхода в управлении инновационной деятельностью. Для решения поставленных задач применялись общенаучные методы: системный и структурно-функциональный подходы, методы анализа и синтеза, сравнения и абстрагирования, экспертных оценок и др.

Так, контент-анализ работ [3-9] показал, что в большинстве своем под инновационной экосистемой понимается некоторая платформа «взаимодействия» как подвижная совокупность причинно-следственных элементов определенных типов и их устойчивых отношений, связей, которые обеспечивают в своем целостном единстве трансформацию идей, знаний, информации, ресурсов в успешные инновационные продукты, проекты. С позиций системного подхода ИЭС представляет собой, прежде всего, совокупность объектов (сообществ участников, их сети) и среды их взаимодействия [4,5]. Экосистемное мышление расширяет представление о механизмах создания открытых инноваций и рынках их использования [10].

В современных условиях масштабирования технологических процессов синтез обозначенных подходов к пониманию сущности ИЭС позволил позиционировать ее как динамичное сетевое самоорганизующееся сообщество, создающее через синергию знаниевых, информационных, ресурсных, технологичных потоков необходимые условия для разнообразных коллабораций участников процессов создания, распространения, коммерциализации и диффузии инноваций на непрерывной основе [11]. При этом важно отметить, что снижение степени целевого регулирования условий существования подобной системы приводит к запуску процессов ее разрушения [12]. В связи с этим для обеспечения устойчивости динамики развития ИЭС и эффективности генерируемых ею процессов и результатов необходимы таргетированные механизмы, позволяющие целенаправленно интегрировать инновационную активность всех субъектов ИЭС в единое пространство создания и воспроизводства инноваций, максимально реализовать их инновационный потенциал в изменяющейся динамике средового взаимодействия.

Понимание важности данных процессов приводит к необходимости научного осмысления компонентов, ключевых характеристик, условий формирования и реализации подобных механизмов ускорения инновационной активности российской экономики и ее подсистем под постоянным воздействием критических факторов, связанных с технологическими трансформациями в мировом сообществе, с потребностью в соответствующем им новом качестве развития национального хозяйства, а также с низкой эффективностью инновационных процессов на всех уровнях хозяйствования [14].

Pезультаты и обсужсдение / Results and discussion. Понятие механизма является обязательным атрибутом динамики любой системы, инструментом обеспечения целенаправленности ее деятельности. Данная категория имеет место в любой среде (живой и неживой), где возникает необходимость оказания воздействия для достижения определенного результата [13]. Механизм имеет широкое распространение и в управленческой практике. Он рассматривается с разных точек зрения: как система, внутреннее устройство, определяющее порядок осуществления того или иного вида деятельности; совокупность правил, законов и процедур, которые обеспечивают правильное функционирование системы, а также взаимодействие ее участников; совокупность процедур принятия управленческих решений; комплекс управленческих решений по достижению поставленных целей.

В инновационном менеджменте также сложилось несколько подходов к решению проблем внедрения инновационных решений, проведения целенаправленных и необратимых изменений инновационного характера посредством построения и использования механизмов инновационно- 
го развития, управления инновационным развитием, управления инновациями, стратегического управления инновационной деятельностью / инновационным развитием и т. п. [14] Их контентанализ через призму генезиса и развития инновационной экосистемы позволяет нам говорит о необходимости разработки механизма управления ею. Под механизмом управления формированием и развитием ИЭС предлагаем понимать совокупность состояний и процессов, принципов и методов, обеспечивающих необходимую динамику приращения капитала, ресурсов и связей в процессе взаимодействий ее участников, их сообществ по поводу создания, внедрения и коммерциализации инноваций для достижения частных целей инновационного бизнеса и агрегированных целей ИЭС.

Как показывает мировая практика, ядро ИЭС составляют цели; источники новых идей и инновационных проектов (инноваторы, исследователи, ученые, предприниматели, стартапы, исследовательские институты, вузы); потребители этих идей и проектов (государство, бизнес, общество, индивиды); сообщества участников (сообщества мейкеров и талантов, фаблабы, научное, экспертное и бизнес-сообщество, сообщество венчурных капиталистов, сообщество инвесторов и т. п.); центр управления; формы (онлайн, офлайн), платформы (цифровые и физические) и динамика взаимодействия; непосредственно процессы создания, производства, коммерциализации и диффузии инноваций, протекающие в рамках стадий развития стартапов и составляющие технологию инновационной деятельности; инновационная инфраструктура (институциональные структуры (университеты, научно-исследовательские институты, проектные организации), институты развития, в т. Ч. финансовые (различные фонды, гранды, государственные и частные финансирующие организации, бизнес-ангелы) и нефинансовые (технологическая инфраструктура - технопарковые и кластерные структуры, технополисы и иннограды (наукограды), бизнес-инкубаторы и акселераторы, центры трансфера технологий, прототипирования и коллективного пользования, особые экономические зоны; информационно-технологические, маркетинговые, юридические и другие сервисы). Исходя из этого в общем виде действие механизма управления формированием и развитием ИЭС можно представить следующей схемой (рис. 1).

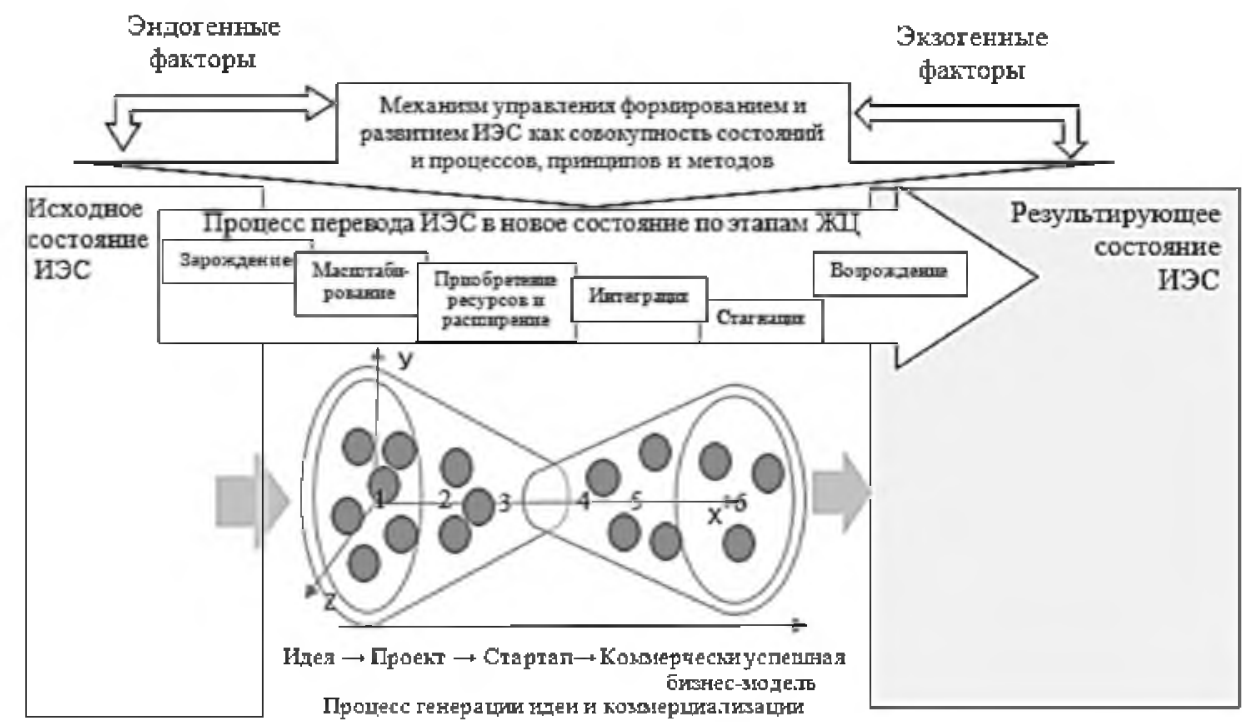

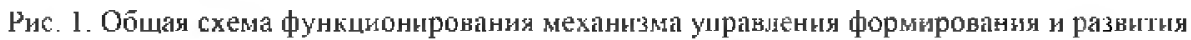
ИЭС (составлсно автором):

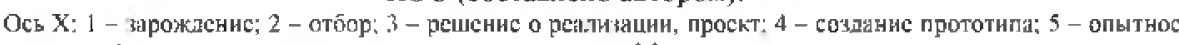

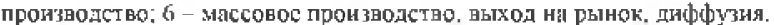

ППласкөсть $Y-Z$ - комыунакация н коллаборацня участннков ИЭС и нх помөшников:

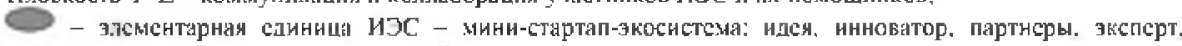
консультант, инвестор, плат|рорыа в занысдействня, систеыа поддержки 
Разработка механизма управления формированием и развитием ИЭС включает:

- выявление инновационных агентов, функциональных и инфраструктурных элементов, составляющих ИЭС;

- определение их целей, ценностей, принципов и необходимых ресурсов для формирования и развития ИЭС;

- выявление взаимосвязей и взаимозависимостей внутри элементов ИЭС, а также с внешней средой;

- установление объемов власти и границ несения ответственности участников ИЭС, определение процедур разрешения конфликтов, противоречий их интересов;

- создание результативной управленческой команды (Центра управления) механизма и обеспечение условий для ее самообучения и формирования базы знаний;

- формирование системы целей, задач, стратегий развития ИЭС и анализ их реалистичности;

- выявление и наращивание конкурентных преимуществ ИЭС по сравнению с другими инновационными экосистемами;

- определение принципов и технологий эффективного управления развитием ИЭС;

- анализ экзогенных и эндогенных факторов инновационной среды и выявление стратегических проблем и лимитирующих переменных развития ИЭС в условиях их постоянного изменения;

- формирование оценочных показателей и периодическую оценку уровня зрелости и потенциала развития ИЭС;

- формулирование и реализацию общих и конкретных функций и методов управления развитием ИЭС;

- необходимое и достаточное обеспечение (ресурсное, в том числе информационное и нормативное-правовое) процесса управления развитием ИЭС;

- формирование и развитие необходимой культуры изменений, культуры принятия неудач и предпринимательских рисков;

- разработку положений и регламентов обеспечения функционирования и развития ИЭС;

- стимулирование связности и обеспечение совместного использования знаний и сети;

- разработку и внедрение интегрированных систем поддержки инновационного предпринимательства и инноваторов;

- таргетированние внутренних и внешних инструментов, регулирующих взаимодействия участников ИЭС и их сообшеств между собой и с внешним окружением;

- оценку эффективности управления развитием ИЭС;

- аккумулирование необходимых компетенций для устойчивого развития ИЭС;

- у установление обратной связи для корректировки и адаптации механизма в режиме самоорганизации в изменяющихся условиях [14]

Поскольку любой механизм представляет собой систему, то в качестве основных составляющих элементов механизма управления формированием и развитием ИЭС можно выделить:

- управляющую подсистему в лице суб์ъекта - внутренние и внешние участники ИЭС, осуществляющие непосредственно или способствующих реализации инновационных процессов;

- управляемую подсистему, представленную такими объектами, как ресурсы ИЭС, процессы и результаты развития ИЭС, среда ИЭС;

- целевую подсистему - цели, критерии и показатели их достижения; 
- функциональную подсистему, отражающую требуемое методологическое обеспечение взаимодействия участников ИЭС;

- обеспечивающую подсистему, включающую формы (онлайн, офлайн) и платформы (физические и цифровые) взаимодействия, методы, способы, принципы, технологии, рычаги и регламенты процессов достижения поставленной цели;

- кросс-функциональные связи между составляющими подсистемами механизма, их элементами и внешней средой.

ИЭС могут быть представлены различными типами [14]. В зависимости от уровня компетенций и территориальной локализации выделяют глобальные ИЭС, национальные, региональные и отраслевые, локальные (корпоративные, межфирменные; индивидуальные). В соответствии с уровнем развития принято говорить о ИЭС зарождающихся, масштабирующихся, привлекающих ресурсы для роста и расширения, интегрирующих, стагнирующих и возрождающихся. Важно понимать, что чем выше уровень компетенций, зрелости и динамики ИЭС и ее окружения, тем больше элементов будет охватывать механизм управления формированием и развитием ИЭС и, соответственно, возрастет роль самоорганизации и автоматизма в осуществлении механизмом своих функций.

Осуществление предлагаемых процедур в рамках обозначенной структуры механизма управления на всех уровнях управленческого воздействия - глобальном, национальном, региональном / отраслевом и локальном (внутрифирменном, межфирменном в рамках кооперации, индивидуальном) - позволит, по нашему мнению, обеспечить взаимодействие и сотрудничество всех участников инновационного процесса. В связи с этим модель структурирования рассматриваемого механизма может быть наглядно представлена рис. 2.

С практической точки зрения любой механизм управления в реальной хозяйственной жизни является всегда конкретным, поскольку направлен на достижение ресурсно и мотивационно определенных целей через каскад управленческих воздействий на конкретные системные объекты в режиме самоорганизации. Его формирование происходит при каждом принятии управленческого решения посредством координации всех элементов частных механизмов управления. Важным аспектом конкретизации и структуризации механизма управления формированием и развитием ИЭС является определение: целей развития ИЭС, целевых интересов ее участников и сообществ, а таюже критериев и показатели их достижения; необходимых ресурсов и компетенций (финансовых, предпринимательских способностей, трудовых, материально-вещественных, информационных, временных, производственно-технических, технологических и др.) для устойчивого развития ИЭС; условий функционирования механизма: запуска, приостановки и остановки механизма; сети обратных связей [14].

Таким образом, механизм управления формированием и развитием ИЭС представляет собой сложное синтетическое образование в результате взаимодействия различных групп частных механизмов, учитывающих структурные, функциональные и динамические ее характеристики в процессе развития в изменяюшейся гетерогенной среде. В первую очередь речь о таких группах механизмов, как механизмы рефлексивного взаимодействия и взаимопроникновения субъектов, механизмы структурной перестройки и модернизации, механизмы администрирования, механизмы экспертизы; механизмы корреляции ресурсов, механизмы сопряжения ресурсов, процессов и участников, механизмы формирования и наращивания инновационного потенциала, механизмы «утилизации» неудачных проектов; механизмы гибкой перестройки системы целей и автоматизма действий по их реализации, функционально-процессные и проектные механизмы; механизмы обеспечения безопасности функционирования ИЭС. 


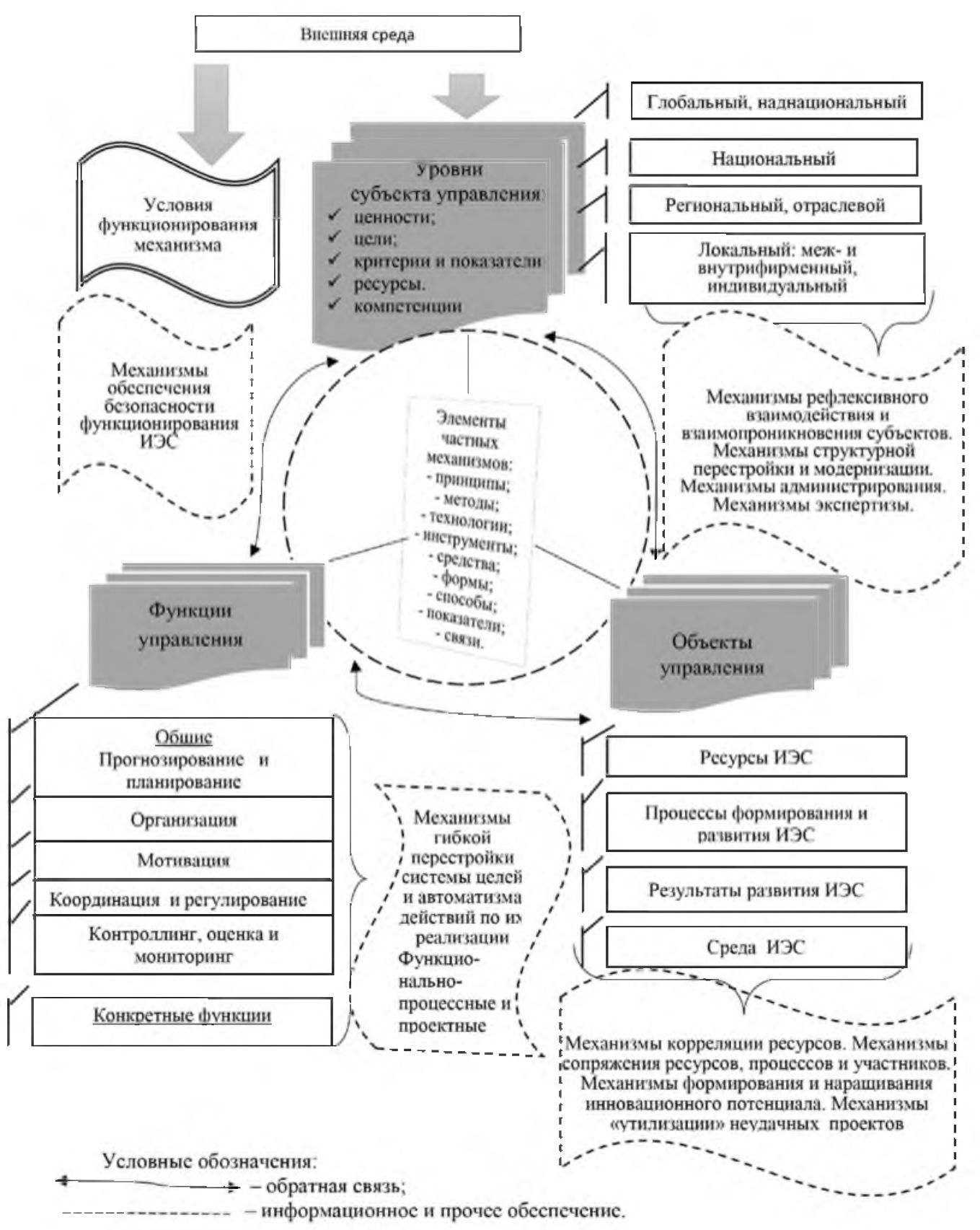

Рис. 2. Модель структуры механизма управления формированием и развитием ИЭС (составлено автором на основе [14])

Заключение / Conclusion. В ходе исследования мы раскрыли возможность решения проблемы устойчивого развития ИЭС за счет создания системы действенных механизмов проактивного взаимодействия и постоянного обновления элементов внутренней среды сообразно внешним изменениям инновационной среды. Сопряжение предложенных структурных элементов механизма управления формированием и развитием ИЭС в режиме самоорганизации и улучшающих преобразований создаст необходимые условия, которые позволят четко идентифицировать объекты 
управления, набор и границы управляющих воздействий в отношении каждого из них; выявлять функционально-структурные характеристики развития ИЭС и их взаимосвязь; определять приоритетные направления и динамику технологического процесса трансформации новых идей в коммерчески успешные бизнес-модели. Все это в совокупности будет способствовать целенаправленному формированию эффективной саморазвивающейся инновационной системы - ИЭС и устойчивому развитию составляющих ее участников и их сообществ для реализации синергетического эффекта в рамках построения инновационной экономики страны.

\section{ЛИТЕРАТУРА И ИНТЕРНЕТ-РЕСУРСЫ}

1. Бакиева М. Ю. Особенности управления инновационной деятельностью строительно-монтажных организаций // Российское предпринимательство. 2015. Т. 16. № 18. С. 3139-3148.

2. Официальный сайт Росстата [Электронный ресурc]. URL: http://www.gks.ru.

3. Венчурные инвестиции экосистема технологического предпринимательства: сб. статей. М.: Изд-во PBK, 2011. - 96 c.

4. Каранатова Л. Г., Кулев А. Ю. Современные подходы к формированию инновационных экосистем в условиях становления экономики знаний // Управленческое консультирование. 2015. № 12. С. 39-46.

5. Клейнер Г. Б. Системная экономика как платформа развития современной экономической теории // Вопросы экономики. 2013. № 6. С. 4-28.

6. Копейкина Л. Экосистема для инновационного бизнеса // The Angel Investor. 2008. Январь. С. 10-13.

7. Смородинская Н. В. Сетевые инновационные экосистемы и их роль в динамизации экономического роста // Инновации. 2014. № 7. С. 27-33.

8. Яковлева А. Ю. Инновационная экосистема - как ключевой фактор успеха «выращивания» малой венчурной компании // Креативная экономика. 2009. № 2 (26). С. $24-28$.

9. Bramwell A. et al. Growing Innovation Ecosystems: University-Industry Knowledge Transfer and Regional Economic Development in Canada // University of Toronto. Final Report. 2012. May 15,

10. Chesbrough H. W. Open Innovation: The New Imperative for Creating and Profiting from Technology // Harvard Business School Press, Boston, MA. 2013.

11. Година О. В., Деньщик М. Н. Особенности формирования и развития инновационных экосистем // THE GLOBAL PROBLEM OF HUMAN SECURITY: economic and legal aspects: The International Scientific and Practical Web-Congress of Economists and Jurists. Ed. dep.: Geneva (Switzerland); Moscow (Russian Federation); Odessa (Ukraine), 2017. 148 p.

12. Суханова П. А. Инновационная инфраструктура в региональной инновационной экосистеме и ее элементы // Вестник СИБИТа. 2012. № 3 (3). С. 49-53.

13. Большой энциклопедический словарь. URL: http://www.vedu.ru/ bigencdic/38501/ (дата обращения: 25.01.2019).

14. Godina O. V. et al. The Structure of the Mechanism of Strategic Management of Innovational Development of Socio-Economic Systemm / O. V. Godina, L. S. Maksimenko, L. I. Ushvitsky, L. V. Slavnetskova, M. N. Denshchik // The Future of the Global Financial System: Downfall or Harmony. 2019. Vol. 57. P. 10941103.

15. Яковлева А. Ю. Факторы и модели формирования и развития инновационных экосистем: дис. ... канд. экон. наук: 08.00.05 / Яковлева Анна Юрьевна. М., 2012. 243 с.

\section{REFERENCES AND INTERNET RESOURCES}

1. Bakieva M. YU. Osobennosti upravleniya innovacionnoj deyatel'nost'yu stroitel'no-montazhnyh organizacij (Features of management of innovative activity of the construction and installation organizations) // Rossijskoe predprinimatel'stvo. 2015. T. 16. № 18. S. 3139-3148.

2. Ofitsial'nyi sait Rosstata (Official website of Rosstat) [Elektronnyi resurs]. URL: http://www.gks.ru

3. Venchurnye investicii ekosistema tekhnologicheskogo predprinimatel'stva (Venture capital investment ecosystem of technology entrepreneurship): sb. statej. M.: Izd-vo RVK, 2011. 96 s. 
4. Karanatova L. G., Kulev A. YU. Sovremennye podhody k formirovaniyu innovacionnyh ekosistem v usloviyah stanovleniya ekonomiki znanij (Modern approaches to the formation of innovative ecosystems in the formation of the knowledge economy) // Upravlencheskoe konsul'tirovanie. 2015. № 12. S. 39-46.

5. Klejner G. B. Sistemnaya ekonomika kak platforma razvitiya sovremennoj ekonomicheskoj teorii (System economy as a platform for the development of modern economic theory) // Voprosy ekonomiki. 2013. № 6. S. $4-28$.

6. Kopejkina L. Ekosistema dlya innovacionnogo biznesa (Ecosystem for innovative business) // The Angel Investor. 2008. YAnvar'. S. 10-13.

7. Smorodinskaya N.V. Setevye innovacionnye ekosistemy i ih rol' v dinamizacii ekonomicheskogo rosta (Network innovation ecosystems and their role in the dynamization of economic growth) // Innovacii. 2014. № 7. S. 27-33.

8. YAkovleva A. YU. Innovacionnaya ekosistema - kak klyuchevoj faktor uspekha «vyrashchivaniya» maloj venchurnoj kompanii (Innovation ecosystem - as a key success factor of "growing" a small venture company) // Kreativnaya ekonomika. 2009. № 2 (26). S. 24-28.

9. Bramwell A. et al. Growing Innovation Ecosystems: University-Industry Knowledge Transfer and Regional Economic Development in Canada // University of Toronto. Final Report. May 15, 2012.

10. Chesbrough H. W. Open Innovation: The New Imperative for Creating and Profiting from Technology / Harvard Business School Press. Boston, MA. 2013.

11. Godina O. V., Den'shchik M. N. Osobennosti formirovaniya i razvitiya innovacionnyh ekosistem (Features of formation and development of innovative ecosystems) // THE GLOBAL PROBLEM OF HUMAN SECURITY: economic and legal aspects: The International Scientific and Practical Web-Congress of Economists and Jurists. Ed. dep.: Geneva (Switzerland); Moscow (Russian Federation); Odessa (Ukraine), 2017. 148 s.

12. Suhanova P.A. Innovacionnaya infrastruktura $v$ regional'noj innovacionnoj ekosisteme i ee elementy (Innovation infrastructure in the regional innovation ecosystem and its elements), Vestnik SIBITa. 2012. № 3 (3). S. 49-53.

13. Bol'shoj enceklopedicheskij slovar' (Large encyclopedic dictionary). URL: http://www.vedu.ru/ bigencdic/38501/ (data obrashcheniya: 25.01.2019).

14. Godina O. V. et al. The Structure of the Mechanism of Strategic Management of Innovational Development of Socio-Economic Systemm / O. V. Godina, L. S. Maksimenko, L. I. Ushvitsky, L. V. Slavnetskova, M. N. Denshchik // The Future of the Global Financial System: Downfall or Harmony. 2019. Vol. 57. S. 1094-1103.

15. Yakovleva A. YU. Faktory i modeli formirovaniya i razvitiya innovacionnyh ekosistem (Factors and models of formation and development of innovative ecosystems): dis. ... kand. ekon. nauk: 08.00.05/Yakovleva Anna YUr'evna. M., 2012. 243 s.

\section{СВЕДЕНИЯ ОБ АВТОРАХ}

Тер-Григорьянц Анна Александровна, доктор экономических наук, доцент, профессор кафедры бухгалтерского учёта, анализа и аудита Института экономики и управления СКФУ. E-mail: ann_ter@mail.ru

Деньщик Марина Николаевна, аспирант кафедры бухгалтерского учёта, анализа и аудита Института экономики и управления СКФУ. E-mail: marina_denshchik@mail.ru

\section{INFORMATION ABOUT AUTHORS}

Anna Ter-Grigoryants, Doctor of Economics, Associate Professor, Professor Department of Accounting, Analysis and Audit of the Institute of Economics and Management, NCFU. E-mail: ann_ter@mail.ru

Marina Denshchik, postgraduate student of the Department of Accounting, Analysis and Audit of the Institute of Economics and Management, NCFU. E-mail: marina_denshchik $@$ amail.ru 